\title{
Understanding Teacher's Perspectives in Media Literacy Education as an Empowerment Instrument of Blended Learning in Early Childhood Classroom
}

\author{
Erie Siti Syarah ${ }^{\mathbf{1}}$ \\ Universitas Negeri Jakarta, Indonesia ${ }^{1,2,3}$ \\ Ilza Mayuni ${ }^{2}$ \\ Nurbiana Dhieni ${ }^{3}$
}

DOI: https://doi.org/10.21009/JPUD.142.01

Accepted: August $15^{\text {th }} 2020$.Approved: September $4^{\text {th }} 2020$. Published: $30^{\text {th }}$ November 2020

\begin{abstract}
Teacher's abilities to understand the benefits and use of media literacy play an important role in dealing with children as digital natives. Media literacy education can be an instrument through the use of blended-learning websites to address the challenges of education in the 21 st century and learning solutions during and after the Covid-19 pandemic. This study aims to figure the teacher's perspective in understanding media literacy as an instrument for implementing blended-learning in early-childhood classes. Using a qualitative approach, this study combines two types of data. Data collection involved kindergarten teachers, six people as informants who attended the interviews and twenty-six participants who filled out questionnaires. Typological data analysis was used for qualitative data as well as simple statistical analysis to calculate the percentage of teacher perspectives on questionnaires collected the pandemic. The findings show five categories from the teacher's perspective. First, about the ability to carry out website-based blended-learning and the use of technology in classrooms and distance learning is still low. It must be transformed into more creative and innovative one. Encouraging teacher awareness of the importance of media literacy education for teachers as a more effective integrated learning approach, especially in rural or remote areas, to be the second finding. Third, national action is needed to change from traditional to blended-learning culture. Fourth, the high need for strong environmental support, such as related-party policies and competency training is the most important finding in this study. Finally, the need for an increase in the ease of access to technology use from all related parties, because the biggest impact of the Covid-19 pandemic is on ECE, which is closely related to the perspective of teachers on technology. The research implication demands increase in technology systems and connections between educators, parents, institutional managers, and education policy holders, for ECE services in urban areas for disadvantaged children, and all children in rural or remote areas.
\end{abstract}

Keywords: Blended Learning, Early Childhood Classroom, Media Literacy Education

\footnotetext{
${ }^{1}$ Corresponding Author:

Department of Early Childhood Education, Doctoral Program

Universitas Negeri Jakarta

Email: ErieSitiSyarah_9920919003@mhs.unj.ac.id
} 


\section{INTRODUCTION}

Early childhood education during a pandemic for an archipelago country like Indonesia makes the effects of this outbreak even worse, because rural areas are wider than urban areas. Preparation of teacher competence for 21 st-century skills in this country has not been completed, related to technology implementation in learning in classes, especially in rural areas. The pandemic period is an accelerating moment of increasing teacher mastery in this field. However, this is a challenge that has not been handled properly. Problems with early-childhood education and development are growing everywhere in this country, due to widespread digitization to discuss the decline in education caused by school closures, but not in line with adequate supervision of the use of technology, and low technology competency of educators, resulting in negative effects on learning outcomes, which is quite large. Learning goals are often not achieved well, so is in assessing children's development. Teachers do not have technology applications to assess children's development, many teachers are not familiar with digital devices, especially teachers in rural areas. Papadakis et al., (2020) says educational applications offered as tools are often made with limited advice from educators or development specialists, so they have little or no value at all. So that his research to the development and exploration of Evaluation Tool for Educational Applications (ETEA) produces a structure that includes four factors, like usability, efficiency, parental control, and security in children's education evaluation tools, can be an example of a solution making similar to help parents, and current teacher.

Although sometimes the use and access of technology and communication become an obstacle and a challenge for teachers to improve the quality of learning, but like previous research on teachers' understanding of technology that has been done by Kalogiannakis and Papadakis (2019), in testing the use of the Technology Adoption Model (TAM) to explore how the skills of kindergarten teachers, ICT (Information and Communication Technology) pre-service children and their attitudes towards the use of mobile devices affect their ability to use it, and it has been shown that pre-service teachers' attitudes towards the utility of mobile learning in the teaching process have the greatest influence on their plans to supports digital device, followed by perceived ease of use. This is because there are many ICT tools that teachers can use to support the teaching and learning process, and this is a big hope for many teachers in rural areas.

Major changes in information and communication technology (ICT) have given rise to new forms of literacy, which are called computer literacy or Internet literacy as a form of media literacy (Livingstone, 2013). Media literacy has the potential to change outcomes in various fields, including education, and communication (Arke \& Primack, 2009). Domine (2011) identifies media literacy education as an important framework for accommodating many kinds of knowledge, skills, and dispositions that are technologically advanced, pedagogically proper, and flexible with design. Media literacy education emergence as a discipline has broadened the traditional definition of media literacy as the ability to access, evaluate, produce and communicate using various forms of media. However, sometimes the use and access of technology and communication become an obstacle and a challenge for teachers to improve learning quality.

It includes teacher flexibility to children with increased work commitment; teacher skills such as modern communication and collaboration methods, the direct access teachers offer to knowledge, and the understanding teachers generate if they are to support learning appropriately. Especially during the Covid-19 pandemic, children have been involved a lot with technological device, children as digital natives will need further stimulation related to technological devices. So, when this difficult time ends, teachers must have skills to carry out traditional learning that is integrated with new technology in the classroom. Website-based blended learning can be an option developed to help teachers give blended learning materials with media literacy disciplines. Briquet-Duhazé (2019) study provides information from the results of his research that helps to build a blended learning website. The goal is to cut learning difficulties of elementary school students by proposing research results and tools for the classroom.

Media literacy education offers a potential tool for correcting corrupted truth (Truth Decay) which is defined as the diminishing role of facts, data, and analysis in current political and civil discourse (Huguet et al., 2019) . However, the field of media literacy education requires educators 
to bridge the relationship between traditional education and computer education. The research of Valtonen et al., (2019), provides an overview of some of the current media computing mechanisms and provides a new perspective for media literacy education to increase students' readiness to face modern media and become critical and skilled actors to navigate the landscape. Media today, teachers' understanding of media literacy is very important. Friesem and Friesem (2019) check media literacy development as a field of study and practice. Their results show the need to re-evaluate the paradigm that has formed media literacy education foundation since its emergence in the field, where teachers have not been heavily involved due to limited understanding. Redmond (2015) finds media literacy is common sense to bridge the core standards of traditional learning with digital media learning experiences, with the right teacher competencies.

Liene (2016) research explores media literacy as a key component of the agency learning process and explains the agency empowerment mechanism through the media education process, so that media literacy is proven to be a tool in the process of empowering learning models. Encouraging the needs of academics in pre-school classes makes teachers have many things requirement to help children focus on class activities. Blended Learning can be a strategy that helps students engage in class. This type of learning increases teacher's flexibility in teaching to focus more on personalization and differentiation based on children's needs, also accommodating the use of technology that children like as digital natives.

Based on research on blended learning (Bryan \& Volchenkova, 2016; Chan, 2019; Chou \& Chou, 2011; Rasheed et al., 2020; Ustun \& Tracey, 2020; Yuen, 2011) researchers recognize developing media literacy education importance (Cappello, 2019; de Abreu, 2010; Kupiainen, 2019; Livingstone, 2013) as a web-based learning tool / instrument (Briquet-Duhazé, 2019; Crawford, 2017; Kennedy et al., 2017; Sabirova et al., 2019) which answers the challenges of 21 st century learning as a complement to learning online which is an important fill for digital native children. To Fill the research problem gap, the research aims to find out the teacher's perspective on media literacy education as an empowering instrument for blended learning websites in early-childhood classes. It is interesting to look at so that the teacher's perspective can be used research a basis for further research, which results in various learning products for early childhood according to the challenges of the times.

\section{THEORITICAL STUDY}

\subsection{Media Literacy Education}

Media and digital technology are seen as tools to support the teaching of traditional disciplines, according to an instructional technology approach that has nothing to do with media literacy. Media literacy is not defined as a mere skill set, with clearly stated pedagogical objectives and performance appraisal systems, but as a new teaching culture in which technology is expected to transform schools into innovative, student-centered, and interactive learning environments. Media is no longer considered only as a tool for teaching and learning but, more broadly, as part of the social and cultural environment of children. Given the lack of a specific discipline dedicated to media literacy, teachers and schools need to develop interdisciplinary projects (Cappello, 2019).

Finland is one of the top countries in the world when it comes to literacy, due to its strong education and teacher education policies. In addition, media literacy is supported by the Ministry of Education and Culture and other government agencies. Among the members of the European Union (EU), Finland is one of the few countries that have a well-developed media literacy policy. In 2013, the Ministry of Education and Culture launched cultural policy guidelines that promote media literacy among children and adolescents. The 2013-2016 National Policy Guidelines for Good Media Literacy cover four topics; (1) high-quality, child-centered and youth-centered daily media education; (2) sustainable structures that promote media literacy achieved through national and local-level legislation, financial resources, and steering; (3) activities and various stakeholders in the media education profile itself. Networks are strengthened, and new partnerships are created; (4) Finland plays an active role in global media education activities (Kupiainen, 2019). 
The educational needs of the 21 st century teachers require a broader definition of technology to include object, print, audio, video, and digital media. A more appropriate terminology for teacher preparation is media literacy because it covers various technologies through which students' access, analyze, evaluate, produce, and communicate information, not just framing it but the use or acquisition of technological skills. Media literacy education can help students, and teachers better understand and communicate their views on 21 st century mathematics, science, technology, social studies, English, and literacy (Partnerships for 21st-Century Skills). For example, Project looks Sharp's Curriculum magnifies the interdisciplinary nature of media literacy education, the inclusiveness of media and technology, and its emphasis on critical thinking and moral decision making (Domine, 2011).

\subsection{Blended Learning with Online Technology}

Blended learning is widely considered an approach that combines the benefits provided by in person and online learning components. Several studies have highlighted the overall challenges of blended learning modes as a whole, but there is no clear understanding of the challenges that exist in the online component of blended learning. Self-regulation challenges and challenges in using instructional technology are the main challenges faced by students. The teacher's challenge is mainly in the use of technology for teaching. Challenges in providing suitable learning technology; and effective training support for teachers is a major challenge faced by educational institutions. Rasheed et al.,(2020) underscores the need for further investigations to address the challenges of students in schools, teachers and educational institutions in blended learning.

Adopting blended learning to involve children in active learning and improving learning outcomes is the result of the development of Internet technology, but this mixed learning dilemma has been proven through research Chan (2019) which shows that participants who still choose in person learning rather than e-learning, they demonstrated a strong preference for traditional modes of learning. Students have intense cultural roots in conventional learning. This often happens in rural areas that have not fully accepted technological developments. In fact, education has shifted where, when and how learning occurs, which is a significant reason why online learning is increasingly accepted (K. Zhang \& Bonk, 2019). Learning with technology has the potential to provide flexible applications that are open to be used as a tool for active, collaborative learning and remove the boundaries of traditional learning. Chou and Chou (2011) state that the limitations of online learning, such as students having difficulty managing time, commitment and maintaining motivation, have been overcome by a mixed learning model as an effective alternative learning (Wu et al., 2010). The results of Ustun and Tracey's (2020) research show that the recurrent study, design and assessment of the resulting blended learning gave researchers the opportunity to find suitable solutions to any real-world problems faced by teachers in the classroom. In addition, the design and implementation of blended learning lead's teachers to move from a passive approach to an active teaching approach and encourages students across three iterative cycles to become mobile and interactive learners.

Blended learning in the 21 st century is learning related to technology. Media literacy education can be the key to improving learning without censoring students. Media literacy can make it easier for educators to develop children as competent digital natives. De Abreu's (2010) research contributes to the case of media literacy education when technology enters schools, homes, and globally as a means to empower digital indigenous children, or in other words media literacy education can be an instrument of empowering blended learning related to technology. Recent research has provided many technological applications to support mixed learning in early-childhood classes. However, Papadakis and Kalogiannakis (2017) review concluded that despite thousands of applications available today, it is difficult and inconvenient for teachers and parents to choose the most suitable educational applications for children It may be that mobile devices can increase the impact of education. However, longer duration of interventions, closer alignment of technology and curriculum, and further evaluation of higher-level skills need to reinforce the actual impact of mobile learning programs (Papadakis, 2018). 
Apart from the importance of the ideal perspective of teachers in media literacy through technology to support mixed learning, teachers need to have the ability to select applications used in class. Research by a technology expert related to early-childhood education from Greece provides recommendations to teachers through a review of relevant literature so that before using educational applications, they first evaluate the application. A rubric (abbreviated as REVEAC) in four areas: content, design, functionality, and technical quality, can be used as a reference for evaluating an application for children, this can be studied further in Papadakis's et al., (2017) research article.

\section{METHOD}

This phenomenological research uses qualitative methods. With purposive sampling, researchers deliberately select people who understand the central phenomenon. The participants are ECE educators in the South Tangerang area. Involving thirty-two teachers, six samples that met the criteria to be interviewed in this study, the remaining twenty-six people were asked to fill out a questionnaire with the same concept of the instrument. Interviewees are asked to take part in voluntary interviews and sign a consent form showing that they can be opt out at any time.

The researcher did not force the code to fall into certain categories, but the participants had responses that were quite similar where no different cases were found. The research questions in this study are outlined as follows, RQ1: How do teachers carry out media literacy education through web-based blended learning today? RQ2: What are the challenges for teachers in facing the demands of technology-based and traditional learning? RQ3: What is the teacher's perspective on the aspects of media literacy education, learning, and website-based technology?

\subsection{Instrument}

Teachers must be technology literate individuals and must have the skills and experience they need to use in teaching activities. One of these technology standards is the ISTE National Educational Technology Standard (NETS-T) and indicators of teacher achievement in technology literacy are contained in 5 standards and 20 sub-items, used as references in the semi-structured interview instrument. Likewise, with the instruments in the questionnaire, by modifying (adjusted to the situation of teachers in Indonesia) and applying the instruments in the ISTE National Education Technology Standard (NETS-T) on the list of statements in this research questionnaire. The content of this research instrument has been validated through a construct validity test with an expert judgement by an educational technology expert. The reliability test was carried out by arranging two similar instruments (equivalent), then being tested on the same group of respondents, and the test results were correlated with the product-moment correlation technique.

Table 1. Teacher's Perspectives on Media Literacy (adapted from Aktay, 2009)

\begin{tabular}{|c|c|c|}
\hline $\begin{array}{l}\text { Media Liter- } \\
\text { acy Cycle }\end{array}$ & $\begin{array}{l}\text { Proficiency in Tech- } \\
\text { nology (ISTE, 2009) }\end{array}$ & Teacher Technology literate \\
\hline Perception & & $\begin{array}{l}\text { 1. Understanding the definition of media literacy } \\
\text { 2. Ability to analyze media texts and produce and publish } \\
\text { instructional media content }\end{array}$ \\
\hline Access & $\begin{array}{l}\text { Do research \& use } \\
\text { information }\end{array}$ & $\begin{array}{l}\text { 3. The ability to find information on various resources } \\
\text { 4. Can Motivate student interest in learning } \\
\text { 5. Connect with students' personal interests, culture or expe- } \\
\text { riences outside of school } \\
\text { 6. Gaining prior knowledge of students }\end{array}$ \\
\hline Analysis & $\begin{array}{l}\text { Critical thinking, } \\
\text { problem solving, and } \\
\text { making decisions }\end{array}$ & $\begin{array}{l}\text { 7. Lead and manage productively } \\
\text { 8. Always discuss with children } \\
\text { 9. Using the principles of Bloom's Taxonomy } \\
\text { 10. Case study method } \\
\text { 11. Reflection }\end{array}$ \\
\hline Evaluation & & 12. Empathic disposition \\
\hline
\end{tabular}




$\begin{array}{ll}\text { Result / Out- } & \text { Using technology ef- } \\ \text { come } & \text { fectively and produc- } \\ & \text { tively }\end{array}$

Delivery Communicate and
collaborate
13. Digital reflection technique

14. Share thoughts in pairs

15. The use of mixed learning models and facilitates the effective use and collaboration of current and emerging digital tools

16. make meaningful assessments that are consistent with identified learning objectives and enforced learning activities.

17. Engage in formative and summative assessments.

18. Use of oral, written and digital communication models that are effective and appropriate for students, parents, colleagues, and community members.

19. Digital citizenship

\subsection{Data Collection and Research Procedures}

Interview data were collected through several semi-structured and open-ended questions posed to teachers and five administrator questions over a 45-60-minute period. At the end of each interview, researchers emailed a copy of the transcription results to participants to verify their own responses. Participants were also asked to check the appropriateness of the findings in their setting. The researcher gives an open invitation to the interviewer to discuss the findings after the interview. Researchers ensure correct information records on interview forms that are processed through Google Documentation. Audio recordings were played back within 24 hours after each interview to compare with typed data. Participants will have access to the final publication of the research study. Arrangements for a 45-60-minute open question and answer session were made online due to the COvid-19 pandemic situation. Its purpose is to allow interviewees to select locations to make sure convenience and transparency. The time period the interviews were conducted after a period of distance learning for teachers and students because qualitative research is most effective when it is conducted in a natural environment. The questionnaire as a source of quantitative data, was distributed via Google form and distributed to 26 early childhood education teachers in the alumni community of graduates of the S1 early childhood teacher education program.

Before starting the interview, permission was obtained from the school district and participants. Further steps such as describing the research, identifying risks, maintaining confidentiality and providing informed consent have been taken. There was a minimal risk anticipated for the participants in this study. All demographic information was removed from the data collected and a pseudonym assigned. Participants were told that the study was completely voluntary, and withdrawals could occur at any time. Participants were given some protection during the interview starting with their identities kept secret.

\subsection{Qualitative Data Analysis}

Typological analysis begins by identifying the research category organizing framework, a series of perspectives on media literacy to the perspective of using website-based technology, based on the main ideas before presented in the aspect of media literacy as an instrument for empowering website blended learning in the research background section.

Semi-structured interviews and questionnaires were used as the main source of data. Accurate and well-defined research questions are used to support credibility in research. The questions included in this study come from a conceptual framework and validated instrument adoption. All information relates to the research question and is aligned with the aim of exploring teacher perspectives on media literacy as a web-based blended learning tool. After writing the interviews results, the researcher compared the transcripts with the audio recordings for accuracy and to check, clarify, and make sure the accuracy of the data collected using member checking, audit trail processing (dependability) and data triangulation (confirm ability). With peer-debriefing, researchers and external sources communicate to note differences that do not support patterns and 
themes derived from data analysis for interviews and questionnaire, which are then compiled with the thick description (transferability) results. During member checking (credibility), participants can check what they said during the interview. No other edits or interview required after the process is complete. Researchers also document information that is not in line with general themes.

\subsection{Quantitative Data Analysis}

Furthermore, to help find sources of similarity and variation to form the first source group, statistical analysis was carried out from a questionnaire, measuring the perspective of the group teacher $(\mathrm{n}=26)$. Composite and sub scale measures were created that averaged the responses to five-point Likert's data, so that a score of one was equivalent to 'never is misunderstood', and a score of five was equal to 'always is very well understood'. Classification was determined using the average score across all survey responses.

\section{RESULT AND DISCUSSION}

\subsection{Quantitative Result}

The data from the questionnaire is presented in the form of a donut diagram, which is the result of calculating the average presentation of participant responses about media literacy. The data show a presentation that corroborates the qualitative data for the teacher's perspective covering the first categories of the study. The results are shown by the code Q1 to Q22, the number of Q in accordance with the questions raised in the Google form questionnaire (Percentage of Participant Responses shown in Figure 1).

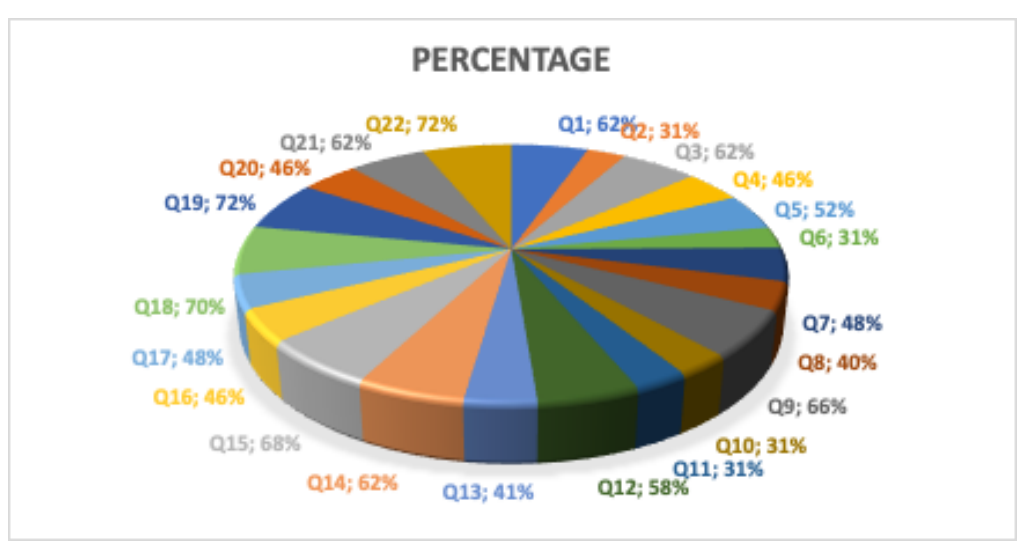

Figure 1. Percentage of Participant Responses

The results of the research findings, such as in question number 1, Q1: show that $62 \%$ of participants understand that media literacy is a means of analyzing media texts, producing and publishing instructional media content. Q2: $31 \%$ of teachers understand media content and media culture, as well as expression and production of early childhood learning media, meaning that teachers in South Tangerang are still limited in understanding the concept of media literacy. Q3: $62 \%$ of teachers find information in various resources, as material for teaching, meaning that $38 \%$ of teachers have difficulty finding information as teaching materials and inspiration for teaching.

Then in the Q4 data: 46\% of teachers stated that they could motivate children's interest in learning activities, related to the remaining $54 \%$ of being unable to motivate children's interests, it was answered in the results of qualitative data analysis in the discussion. Q5 show data $46 \%$ of teachers stated that they understand the personal, cultural, or experiences of children outside of school related to the use of technology. Q6: Only 31\% of teachers know the child's knowledge before learning through media literacy discipline.

Data Q7: $46 \%$ of participants stated that they could lead and manage classes and carry out productive learning using literacy media. This result is still below $50 \%$, it is worth doing further 
research to find the causes of teachers inability to manage classes with learning models, especially those based on websites, whether it is related to the ability to change from traditional to innovative which has not been well developed. Data Q8: The teacher conducts discussions with children about the media used and learning activities. About $40 \%$ of teachers carry out these in the Q9 data: is data that questions the use of the principles of affective, cognitive and psychomotor development in implementing learning through media literacy by teachers, with $46 \%$ results, this shows that early-childhood teachers still have the ability in using learning models, so that they stay without leaving one of them (online learning and traditional learning).

Data Q10: questions in the evaluation category, the teacher's ability to reflect after the learning activity is complete, shows about results, namely $31 \%$. Data Q11: $31 \%$ recorded familiar behavior and understanding of all media and communication used in early-childhood education institutions. Ease of access to the use of technology and digital devices in institutions where teachers work requires better improvement. Data Q12: in the range of presentation values of $46 \%$, this is the behavior of teachers on technology, are teachers friendly to media and communication. Looking at the results of data calculations, it can be concluded that the strength of support and ease of access to technology in Indonesia is still the toughest challenge for media literacy education as a learning media instrument. Data Q13: the ability of teachers to develop activities related to media literacy, shows the percentage of $31 \%$, so answering questions about literacy in Indonesia is still low.

In Q14: the teacher's ability to do digital write reflective journals about child development is at $62 \%$, this shows that there is a potential for understanding that media literacy in teachers that can be improved with better perspective interventions. The form of intervention can be carried out with a concept that is easy to make so that the targets of increasing the understanding of media literacy in teachers are achieved. Data Q15: 62\% of teachers stated that they shared their thoughts with other teachers in evaluating learning. Q16: $46 \%$ of teachers stated that they could model and help effective use and collaboration of existing and emerging digital tools.

Looking at $46 \%$ of the Q17 data: the teacher stated that he could make meaningful assessments that were in accordance with the identified learning objectives and the website-based learning activities carried out. Q18 data: teachers who can always be involved in formative and summative assessments are $31 \%$. Q19 shows data on the use of an effective and proper oral communication model for children, parents, colleagues, and community members with a total of $31 \%$. Then the Q20 data: $46 \%$ of teachers choose to use a written communication model that is good for children, parents, colleagues, and community members. Q21: It shows $62 \%$ of teacher stated that they have used a digital communication model is effective and right for children, parents, colleagues, and community members. Finally, Q22: 46\% of teachers can understand children as digital natives.

\subsection{Qualitative Result}

The qualitative data illustrates the various responses about media literacy as an instrument for empowering blended learning results from interviews. An excerpt from the interview is attached to the discussion, so that it can immediately complement the research findings. The patterns, relationships and themes are discussed in line with the three research questions that guide this research. Based on the analysis of the combined data for this teacher's perspective, patterns of similarities and differences between them within each source group and between the source groups are identified. These patterns are derived based on main order, perspective, access, analysis, evaluation, results / results, understanding of media literacy with qualitative and quantitative claims in web-based learning practices. Finally, five 'ideal types' (typologies) were determined based on 'patterns of similarity and difference' (see Table 2 for a summary of the results of the analysis).

Table 2. Typology Analysis Results

\begin{tabular}{ll}
\hline \multicolumn{1}{c}{ Typology } & Code \\
\hline Teacher's perspective: must be transformed into creative and innovative & Typology 1 \\
The importance of media literacy education for teachers as a more effective integral & Typology 2 \\
learning approach & \\
\hline
\end{tabular}




\begin{tabular}{ll}
\hline $\begin{array}{l}\text { National action is needed to change from a traditional learning culture to Blended } \\
\text { Strength of environmental support with stakeholder policies (comprehensive train- } \\
\text { ing) }\end{array}$ & $\begin{array}{l}\text { Typology } 3 \\
\text { Typology } 4\end{array}$ \\
$\begin{array}{l}\text { The need for an increase in the ease of access to technology use from all related } \\
\text { parties }\end{array}$ & Typology 5 \\
\hline
\end{tabular}

\subsection{Discussion}

The results of the research findings answered research questions in which there were typology results discussed in this section with their limitations, typology presentation numbers were not sequential because it followed the flow of research questions (PP). There are three Research Questions (PP) that will be used as a reference in the research discussion section, the first research question is answered through the findings of typology 2 and 3. Typology 5 and four answer the second research question, and the last research question are answered through the content of typology 1 .

\subsubsection{RQ1: How do teachers carry out media literacy education through web-based blended learning today}

4.3.1.1 The Importance of Media Literacy Education for Teachers as A More Effective Integral Learning Approach

Descriptions of the research findings, both the results of questionnaires and interviews with key informants, related to media literacy education application in the perspective of early childhood teachers in South Tangerang, are still quite apprehensive in the era of competitive global technology. Implementing media literacy condition as a website-based blended learning empowerment is not yet widely known at the early-childhood teacher level. On average, they are not familiar with the term media literacy as a number of specific competencies, such as the ability to reach, analyze, evaluate, and communicate media messages in various forms (Huguet et al., 2019) or the term learning, even though they have practiced some of the concepts. As stated in the following interview excerpt:

" I am still unfamiliar, now our learning in school traditional programs and occasionally using website-based learning. After entering the pandemic period (starting March 2020), learning has changed completely to only online from home, this makes parents overwhelmed, because blended learning socialization has not yet reached parents." (Participant interview (P1, [30/6 23:20]).

The data from the questionnaire showed that the presentation was below $50 \%$ for the item of teacher understanding of media literacy, which is a means of analyzing media texts, producing and publishing instructional media content. Consistency in implementing the discipline of implementing media literacy education as a learning instrument in early-childhood classes has not been maximally carried out, referring to the findings. It has not been able to consistently use the blended learning process. The findings also show that media literacy education has not been fully implemented. The reason researchers currently researching media literacy integration and blended learning are given the words of L. Zhang et al., (2020) which state that implementing media literacy education as an integral approach is more effective than simply applying media literacy education as an isolated subject. At the same time, it is a challenge for educators to embed media literacy programs as an integral of education.

Media literacy education can be an empowering instrument website-based learning models at this time, from the perspective of teachers in Indonesia. It is still something that is considered luxurious and difficult to start. Meanwhile, the contemporary education paradigm determines the transition from investment aspects (duration, place, teaching method) towards learning outcomes that are closely related to active learning, experiences, which support the need for new types of partnerships, such as, social partners involvement, and types promotion of cooperation between schools and family. 
A person who is able and willing to be involved in the social process, can put forward his own goals and make these goals flexibly, while adjusting to the situation and using available resources, is the result of learning and can be defined as an agent (Liene, 2016). The researcher hopes that various related parties will be help find answers to the main goals of media education, media education content, how media education should be integrated into didactic pedagogy and the teaching and learning process, because of surveys in the early-childhood education field, teachers' understanding is still not evenly distributed from the perspective of media education.

\subsubsection{National Action Is Needed to Change from A Traditional Learning Culture to Blended}

The research findings from the questionnaire results, only recorded $31 \%$ in familiar behavior and teachers' understanding of every digital communication media used in early-childhood education institutions, which led to the change from traditional to, resulting in slow learning targets. This is caused by various factors, in the following interview excerpt:

"Other fellow teachers seem less familiar with website-based learning, and the difficulty in using technology makes teachers often switch back to traditional learning, sometimes due to circumstances, or fewer diligent personal teachers. Actually, there are several websites for learning references, it's just that we never fixate on one of them, when we get stuck, we don't continue" (Participant interview (P2, [30/6 23:30]).

The traditional education culture is so inherent, that media literacy education is hidden from view. It is not realized that media literacy education has run in the classroom. However, media literacy as a website-based learning instrument requires a clear concept of practice. Children are often asked to use media content or information from the Internet and television, study cartoons, advertisements, pamphlets, and other resources that offer primary source information (Wan \& Gut, 2008). Teachers can use media literacy education to hone children's abilities to value media as a source of evidence. In addition, media literacy education can foster students' analytical and reasoning skills.

\subsection{RQ2: What are the challenges for teachers in facing the demands of technology-based and traditional learning?}

4.4.1.1 The Need for An Increase in The Ease of Access to Technology Use from All Related Parties

The findings of the questionnaire and interview data have related results, namely that the ease of access to technology use in early-childhood classes still has significant obstacles. If we compare these findings with the European Commission which defines media literacy as the ability to reach the media, understand, and critically rate various aspects of media and media content, as well as create communication in various contexts (L. Zhang et al., 2020), then teachers ability to understand media literacy is an important agenda before providing media literacy education to children. When access to technology is open, teachers in behavior, and abilities are still at the traditional level and have not changed towards innovative technology. The interview excerpt shows what is common in technology backward countries:

"Sometimes the title fits what we want to find but is locked inaccessible, u sing English in explaining the material and the wi-fi network in the classroom" (Participant interview (P2, [30/6 $23: 43])$.

4.4.1.2 It appears that the obstacles and challenges do not always come from outside, but teachers in understanding competencies the media is a big challenge to fix. The teacher's perspective also on the ease of access to technology use reveals that the important emphasis of this has shifted, starting from technical difficulties such as Internet networks, inadequate digital equipment facilities, etc., currently shifting to easy access to technology use on content quality. Access to quality 
content is still a major obstacle in media literacy education as a website-based learning empowerment instrument.

\subsubsection{Strength of Environmental Support with Stakeholder Policies (Comprehensive Training)}

The excerpt from the teacher's interview in this case shows that environmental support is a major reason in media literacy application of an instrument for empowering blended learning. Because interventions in this field must be designed to meet the needs of people of various ages by understanding the roles and life goals they have throughout their ages (Rasi et al., 2019). Different pedagogical strategies are needed to address children's media literacy competencies. Adopting a life perspective certainly allows an examination of media literacy competencies that develop over time in response to change historical conditions, social institutions and policies.

"I would be very grateful if learning websites appeared that could become references in teaching. For us, it is very helpful when we need a refresher on learning activities, so that finding new ideas so that children don't get bored, this provides support for teachers so that the learning load becomes lighter "(Participant interview (P6, [30/6 23:43])

Media literacy offers teachers and students a set of skills to analyze, criticize, and respond to information that appears before them in digital texts. Many case studies have identified ways in which teachers have integrated media literacy into their instruction. Teacher candidates tend to use constructivist teaching methods that need students, not teachers, to interpret media messages. Recent research shows that ways teacher educators can develop prospective teachers ability to bring media literacy skills to their content area instruction are the closest and strongest support for enhancing teacher perspective and understanding (Cherner \& Curry, 2019).

Media literacy skills can be integrated into curricula to support student learning with positive outcomes (Cheung \& Xu, 2016; Redmond, 2015), with a focus on understanding prospective teachers of how they plan to discuss media literacy in their classrooms in the future can offer now teacher educators about how to prepare them for the job. Thus, educator preparation programs will respond when they are tasked with developing media.

\subsection{RQ3: What is the teacher's perspective on the aspects of media literacy education,} learning, and website-based technology?

\subsubsection{Teacher's Perspective: must be Transformed into creative and innovative}

Although the teacher's perspective is the most important thing in media literacy application as a tool for empowering website-based learning, the findings of this study say that the strongest support is in comprehensive teacher training because teachers are the key actors in the success of blended learning. Teachers' understanding of media literacy is an important factor in transferring the same thing to children to successfully master any school subject. An educator must be able to change from cooperation through training methods, and must also receive quality support in the educational transformation process (Liene, 2016).

Educators must be able to adopt a semiotic perspective on media literacy to focus on helping children gain the knowledge they need and understand it well. Such as, how they influenced by media and how influence others through the original media that they create and share (Schmidt, 2019). Training to improve teacher skills and policies on the use is technology are priorities that need to be considered by many stakeholders. The teacher's perspective on media literacy application as empowering instrument for blended learning can transform teacher understanding to be more innovative.

\section{CONCLUSION}

Referring to the research findings, that the results of interviews and questionnaires have answered research questions, which are divided into five typologies. The results showed five ideal type results, which were the results of typological data analysis as follows; First, about the ability 
to carry out website-based blended-learning and the use of technology in classrooms and distance learning is still low. It must be transformed into more creative and innovative one. Encouraging teacher awareness of the importance of media literacy education for teachers as a more effective integrated learning approach, especially in rural or remote areas, to be the second finding. Third, national action is needed to change from traditional to blended-learning culture. Fourth, the high need for strong environmental support, such as related-party policies and competency training is the most important finding in this study. Finally, the need for an increase in the ease of access to technology use from all related parties, because the biggest impact of the Covid-19 pandemic is on ECE, which is closely related to the perspective of teachers on technology.

The research implication demands increase in technology systems and connections between educators, parents, institutional managers, and education policy holders, for ECE services in urban areas for disadvantaged children, and all children in rural or remote areas. The findings give an insight that there are still many big tasks for academics and policy makers about learning and technology integration. When the pandemic period ends, and early childhood learning returns school, a website-based blended learning model empowerment is expected to have been developed a lot. Exploration of children with technology during a pandemic, must continue in the earlychildhood classroom. Further research is that it can become the basis for research that develops various technology-based learning products as a result of media literacy education and demands an improvement in technology systems and connections between educators, parents, management institutions, and education policy holders.

\section{REFERENCES}

Aktay, S. (2009). The ISTE national educational technology standards and prospective primary school teachers in Turkey. International Journal of Learning, 16(9), 127-138. https://doi.org/10.18848/1447-9494/cgp/v16i09/46607

Arke, E. T., \& Primack, B. A. (2009). Quantifying media literacy: Development, reliability, and validity of a new measure. Educational Media International, 46(1), 53-65. https://doi.org/10.1080/09523980902780958

Briquet-Duhazé, S. (2019). Websites Consulted by Future Primary Level Schoolteachers in France: Differences between Students and Trainees. American Journal of Educational Research, 7(7), 471-481. https://doi.org/10.12691/education-7-7-6

Bryan, A., \& Volchenkova, K. N. (2016). Blended Learning: Definition, Models, Implications for Higher Education. Bulletin of the South Ural State University Series "Education. Education Sciences, " 8(2), 24-30. https://doi.org/10.14529/ped160204

Cappello, G. (2019). Media Literacy in I taly . The International Encyclopedia of Media Literacy, 1-6. https://doi.org/10.1002/9781118978238.ieml0155

Chan, E. Y. M. (2019). Blended learning dilemma: Teacher education in the confucian heritage culture. Australian Journal of Teacher Education, 44(1), 36-51. https://doi.org/10.14221/ajte.2018v44n1.3

Cherner, T. S., \& Curry, K. (2019). Preparing Pre-Service Teachers to Teach Media Literacy: A Response to "Fake News." Journal of Media Literacy Education, 11(1), 1-31. https://doi.org/10.23860/jmle-2019-11-1-1

Cheung, C. K., \& Xu, W. (2016). Integrating Media Literacy Education into the School Curriculum in China: A Case Study of a Primary School. Media Literacy Education in China, 1-179. https://doi.org/10.1007/978-981-10-0045-4

Chou, A. Y., \& Chou, D. C. (2011). Course Management Systems and Blended Learning: An Innovative Learning Approach. Decision Sciences Journal OfInnovative Education, 9(3), 463-484. https://doi.org/https://doi.org/10.1111/j.1540-4609.2011.00325.x

Crawford, R. (2017). Rethinking teaching and learning pedagogy for education in the twenty-first century: blended learning in music education. Music Education Research, 19(2), 195-213. 
https://doi.org/10.1080/14613808.2016.1202223

de Abreu, B. (2010). Changing technology: empowering students through media literacy $\begin{array}{llll}\text { education. New Horizons in Education, } & 26 .\end{array}$ https://files.eric.ed.gov/fulltext/EJ966657.pdf

Domine, V. (2011). Building 21st-Century Teachers: An Intentional Pedagogy of Media Literacy Education. Action in Teacher Education, 33(2), 194-205. https://doi.org/10.1080/01626620.2011.569457

Friesem, E., \& Friesem, Y. (2019). Media Literacy Education in the Era of Post-Truth: Paradigm Crisis. In Handbook of Research on Media Literacy Research and Applications Across Disciplines. IGI Global.

Huguet, A., Kavanagh, J., Baker, G., \& Blumenthal, M. (2019). Exploring Media Literacy Education as a Tool for Mitigating Truth Decay. In Exploring Media Literacy Education as a Tool for Mitigating Truth Decay. https://doi.org/10.7249/rr3050

Kalogiannakis, M., \& Papadakis, S. (2019). Evaluating pre-service kindergarten teachers' intention to adopt and use tablets into teaching practice for natural sciences. International Journal of Mobile Learning and Organisation, 13(1), 113-127. https://doi.org/10.1504/IJMLO.2019.096479

Kennedy, A. B., Schenkelberg, M., Moyer, C., Pate, R., \& Saunders, R. P. (2017). Process evaluation of a preschool physical activity intervention using web-based delivery. Evaluation and Program Planning, 60, 24-36. https://doi.org/10.1016/j.evalprogplan.2016.08.022

Kupiainen, R. (2019). Media Literacy in F inland . The International Encyclopedia of Media Literacy, 1-6. https://doi.org/10.1002/9781118978238.ieml0147

Liene, V. (2016). Media Literacy as a Tool in the Agency Empowerment Process. Acta Paedagogica Vilnensia, 58-70. https://doi.org/http://dx.doi.org/10.15388/ActPaed.2016.37

Livingstone, S. (2013). Media Literacy and the Challenge of New Information and Communication Technologies. The Communication Review, 7(March), 86. https://doi.org/https://doi.org/10.1080/10714420490280152

Papadakis, S. (2018). Evaluating pre-service teachers' acceptance of mobile devices with regards to their age and gender: A case study in Greece. International Journal of Mobile Learning and Organisation, 12(4), 336-352. https://doi.org/10.1504/IJMLO.2018.095130

Papadakis, S., \& Kalogiannakis, M. (2017). Mobile educational applications for children. What educators and parents need to know. International Journal of Mobile Learning and Organisation, 11(2), 1. https://doi.org/10.1504/ijmlo.2017.10003925

Papadakis, S., Kalogiannakis, M., \& Zaranis, N. (2017). Designing and creating an educational app rubric for preschool teachers. Education and Information Technologies, 22(6), 31473165. https://doi.org/10.1007/s10639-017-9579-0

Papadakis, S., Vaiopoulou, J., Kalogiannakis, M., \& Stamovlasis, D. (2020). Developing and exploring an evaluation tool for educational apps (E.T.E.A.) targeting kindergarten children. Sustainability (Switzerland), 12(10), 1-10. https://doi.org/10.3390/su12104201

Rasheed, R. A., Kamsin, A., \& Abdullah, N. A. (2020). Challenges in the online component of blended learning: A systematic review. Computers and Education, 144(March 2019), 103701. https://doi.org/10.1016/j.compedu.2019.103701

Rasi, P., Vuojärvi, H., \& Ruokamo, H. (2019). Media Literacy for All Ages. Journal of Media Literacy Education, 11(2), 1-19. https://doi.org/10.23860/jmle-2019-11-2-1

Redmond, T. (2015). Media Literacy Is Common Sense: Bridging Common Core Standards with 
the Media Experiences of Digital Learners: Findings from a Case Study Highlight the Benefits of an Integrated Model of Literacy, Thereby Illustrating the Relevance and Accessibility of Me. Middle School Journal, 46(3), 10-17. https://doi.org/10.1080/00940771.2015.11461910

Sabirova, E. G., Fedorova, T. V., \& Sandalova, N. N. (2019). Features and advantages of using websites in teaching mathematics (Interactive educational platform UCHI.ru). Eurasia Journal of Mathematics, Science and Technology Education, 15(5). https://doi.org/10.29333/ejmste/108367

Schmidt, H. C. (2019). Media Literacy in Communication Education. The International Encyclopedia of Media Literacy, 1-6. https://doi.org/10.1002/9781118978238.ieml0126

Ustun, A. B., \& Tracey, M. W. (2020). An effective way of designing blended learning: A three phase design-based research approach. Education and Information Technologies, 25(3), 1529-1552. https://doi.org/10.1007/s10639-019-09999-9

Valtonen, T., Tedre, M., Mäkitalo, Ka., \& Vartiainen, H. (2019). Media Literacy Education in the Age of Machine Learning. Journal of Media Literacy Education, 11(2), 20-36. https://doi.org/10.23860/jmle-2019-11-2-2

Wan, G., \& Gut, D. M. (2008). Media use by Chinese and U.S. secondary students: Implications for media literacy education. Theory into Practice, 47(3), 178-185. https://doi.org/10.1080/00405840802153783

Wu, J. H., Tennyson, R. D., \& Hsia, T. L. (2010). A study of student satisfaction in a blended elearning system environment. Computers and Education, 55(1), 155-164. https://doi.org/10.1016/j.compedu.2009.12.012

Yuen, A. H. K. (2011). Exploring Teaching Approaches in Blended Learning. Research \& Practice in Technology Enhanced Learning, 6(1), 3-23. https://www.researchgate.net/publication/229000574

Zhang, K., \& Bonk, C. J. (2019). Addressing diverse learner preferences and intelligences with emerging technologies: Matching models to online opportunities. Canadian Journal of Learning and Technology, 53(9), 1689-1699. https://doi.org/10.1017/CBO9781107415324.004

Zhang, L., Zhang, H., \& Wang, K. (2020). Media Literacy Education and Curriculum Integration: A Literature Review. International Journal of Contemporary Education, 3(1), 55. https://doi.org/10.11114/ijce.v3i1.4769 